\title{
Decision support for long-term water resource management in semi-arid areas: insights from South Africa
}

\author{
W. J. de Lange $^{1} \&$ T. E. Kleynhans ${ }^{2}$ \\ ${ }^{1}$ Western Cape Department of Agriculture, South Africa \\ ${ }^{2}$ Department of Agricultural Economics, \\ Stellenbosch University, South Africa
}

\begin{abstract}
Public goods, such as bulk water supply infrastructure, have proved vulnerable to failures in market and government allocation strategies. Common to both strategies are uncaptured costs and benefits. This implies a measurement problem due to shortcomings in quantification techniques for estimating costs and benefits for different market- and government-driven allocation strategies and led to decisions based on incomplete information. With legitimate decisionmaking depending on reliable information, the measurement problem poses an obstacle to social welfare maximisation. This paper incorporates components of economic valuation theory, multi-criteria decision analysis, a public survey and a modified Delphi expert panel technique to score the multi-criteria attributes and assign weights. The approach was applied in the Western Cape province of South Africa and specifically focused on a choice problem regarding different long-term bulk-water resource management options for the area. The decisionmaking context was broadened to accommodate unaccounted-for costs and benefits in water resource allocation decision-making. Both spatial and temporal dimensions of the decision-making context were expanded. The spatial expansion manifested in the physical expansion of the management area, which led to expansions in representation in the decision-making process. The temporal expansion manifested in the consideration of different sequences of bulk supply schemes over time instead of a selection of schemes at the same time. Two surveys were conducted to accommodate such expansions. The first focussed on public preferences towards long-term water allocation management and the second on inputs of members of an expert panel by means of a modified Delphi technique. Questions regarding whether, and if so, to what extent, the public needed to be accommodated in long-term water resource allocation decisionmaking came to the fore. A broad acceptability towards a willingness to pay for "greener" water was observed and the outcome may be used to motivate a paradigm shift among managers to consider, without fearing harm to their political positions, "greener" water supply options more seriously, even if such options imply higher direct costs.
\end{abstract}

Keywords: water management, decision-support, public participation. 


\section{Introduction}

Unaccounted long-term effects of different natural resource (water) allocation strategies tolerate ignorance of some spatial and temporal dimensions of resource allocation decision-making. The inability to confidently estimate total costs and benefits of different allocation distributions is mainly due to a measurement problem, which promotes failures in market- and government-orientated allocation systems. Consequently, the decision-making context is narrowed thereby hampering the promotion of allocations that support social welfare maximisation. Decision-support techniques including multi-criteria decisionmaking (MCDM) are employed to aid in this regard.

With new bulk supply sources becoming less accessible, more expensive and environmentally less acceptable, new and innovative water management strategies and policies are called for. This paper applies the above-mentioned in the bulk-water allocation decision-making environment of the Berg Water Management Area (BWMA) in South Africa.

\section{Problem structuring and literature review}

The development of bulk augmentation infrastructure leads to re-allocations of water between different uses, users and areas. Such re-allocations are often motivated by price elasticity of demand differentiations with too much emphasis on financial, political and technological impacts and too little emphasis on socioeconomics and environmental impacts of allocation decisions. This leads to ignorance of some of the spatial and temporal dimensions of resource allocation decision-making and defines a measurement problem (see Figure 1). As such, social welfare is unknowingly threatened because the measurement problem narrows the allocation decision-making context with potential adverse effects for social welfare maximisation.

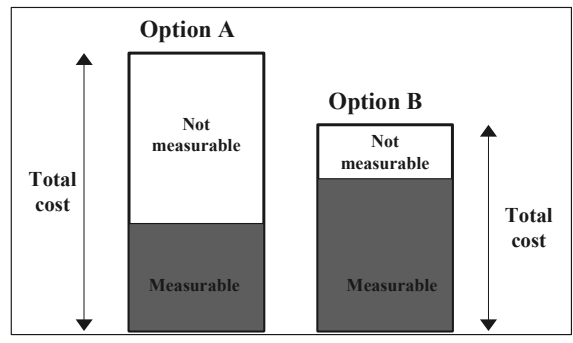

Figure 1: A measurement problem.

Markets have become important resource allocation mechanisms (Arriaza et al. [1], Bateman et al. [3], Bush et al. [5], Colby et al. [7], Dudley [8], Easter et al. [9], Fishelson [10], Fisher [1], Keenan et al. [13], Kloezen [14], Kumar and Singh [15], Louw [17], Nieuwoudt [19]). Such systems sufficiently accommodate individual allocation decision-making, but often fail with public 
goods since social gains/losses are mostly not accounted for in private allocation decision-making (Arrow [2], Bergson [4]).

Preference is given to the "highest and best use" argument in resource scarcity situations (maximising marginal benefit). Given that the perceived value of water use in urban areas exceed rural use, a gradual re-allocation of water from rural to urban areas is expected (Carmichael et al. [6]). Unfortunately, the difference in perceived value are not fully quantifiable and therefore not fully be accounted for in market-driven allocation systems (due to a measurement problem) (Goodstein [12], Mander et al. [18], Pearce [20]). Such systems could therefore not be exclusively used to achieve sustainable water resource allocations, and care should be taken to promote the market as the best water allocation mechanism.

An opportunity for government involvement to account for market failures of public goods is consequently created. However, the measurement problem, together with vulnerability to lobby groups, hidden agendas and the acceptability of using own discretion (which often leads to the misuse of power) results in government failure; hence the need exists to aid government intervention measures that ensure the promotion of social welfare maximisation (Goodstein [12], Livingston [16], Pearce [20], Randall [21]). Decision-support techniques, including multi-criteria decision-making (MCDM), are employed to aid in this regard; however, these techniques should not be seen as guaranteed methods to accommodate all parties, but rather as methods to make resource allocation processes more tangible through making risks and uncertainties more explicit. In addition, such support needs to be refined to allow the confident capturing or at least consideration of unaccounted-for effects (longer-term impacts) in a broader decision-making context.

Broadening the decision-making context will add to the information load of the decision-making process and need an expansion in decision-support techniques. The spatial and temporal dimensions of the decision-making context in the BWMA were expanded in this study. The spatial expansion was accommodated via physical expansions of the decision-making boundaries, while the temporal expansion was undertaken via long-term bulk-water supply development paths. Spatial expansion leads to an increase in the representation of newly included areas. This creates uncertainty as to whether the public should indeed be consulted with regard to long-term strategic water management issues.

\section{Expansion of decision-support}

The above-mentioned expansion is applied in bulk-water resource allocation management in the BWMA, which is one of 19 management areas in South Africa and is situated in the Western-Cape Province of the country. The area is characterized by a Mediterranean climate and strong deterministic water supply (winter rainfall) from April to August. Average rainfall is $348 \mathrm{~mm}$ per year with significant variation ranging between $3000 \mathrm{~mm} / \mathrm{a}$ in the mountainous areas to less than $300 \mathrm{~mm} / \mathrm{a}$ in the northwest of the area. 
The expansion of the temporal dimension was achieved via the creation of two long-term "development paths" and the spatial expansion via broadening the physical context (boundaries) of the decision-making area for bulk-water resource management in the BWMA.

\subsection{Expanding the temporal dimension}

The expansion of the temporal dimension was achievement via the development of two long-term development paths comprised of two alternative sequences of bulk-water supply management alternatives (Table 1) phased in over time. The process was made transparent by involving local decision-makers in the development of the two paths. Although controversial, it does represent two legitimate alternatives for long-term bulk-water supply development in the Western Cape.

Table 1: $\quad$ Two long-term water resource management strategies.

\begin{tabular}{|c|c|c|c|c|c|c|c|}
\hline \multicolumn{4}{|c|}{ Development path A } & \multicolumn{4}{|c|}{ Development path $B$} \\
\hline Water scheme & $\begin{array}{c}\text { Implementation } \\
\text { year }\end{array}$ & $\begin{array}{l}\text { Scheme } \\
\text { capacity } \\
\text { (million } \\
\text { kilolitres) }\end{array}$ & $\begin{array}{c}\text { Total storage } \\
\text { capacity in the } \\
\text { Western Cape } \\
\text { (million } \\
\text { kilolitres) }\end{array}$ & Water scheme & $\begin{array}{c}\text { Implementation } \\
\text { year }\end{array}$ & $\begin{array}{c}\text { Scheme } \\
\text { capacity } \\
\text { (million } \\
\text { kilolitres) }\end{array}$ & $\begin{array}{c}\text { Total storage } \\
\text { capacity in the } \\
\text { Western Cape } \\
\text { (million kilolitres) }\end{array}$ \\
\hline $\begin{array}{l}\text { Current water supply } \\
\text { infrastructure }\end{array}$ & 2004 & & 440 & $\begin{array}{l}\text { Current water } \\
\text { supply infrastructure }\end{array}$ & 2004 & & 440 \\
\hline Berg River project & 2006 & 81 & 521 & Berg River project & 2006 & 81 & 521 \\
\hline Voëlvlei scheme phase I & 2013 & 35 & 556 & Desalination plant 1 & 2012 & 65 & 586 \\
\hline Lourens River diversion & 2016 & 19 & 575 & - & - & - & - \\
\hline $\begin{array}{l}\text { Table Mountain Group } \\
\text { aquifer }\end{array}$ & 2018 & 70 & 645 & Desalination plant 2 & 2020 & 65 & 651 \\
\hline Cape Flats Aquifer & 2026 & 19 & 664 & - & - & - & - \\
\hline Eerste River scheme & 2027 & 8 & 672 & Desalination plant 3 & 2027 & 65 & 716 \\
\hline Desalination plant 1 & 2028 & 60 & 732 & - & - & - & - \\
\hline
\end{tabular}

Development Path (DP) A represents the more "conventional" way of supplying future bulk-water needs. With this development path the tendency exists to first opt for the "less expensive" supply options before consideration is given to "more expensive" options, such as desalination of seawater or recycling to potable standard. Such a strategy could be justified based on, firstly, the potential danger for a politician of making a politically unpopular decision (by opting for "more expensive" options) and, secondly, the current measuring techniques used yield a true and legitimate reflection of the total cost of proposed projects. The question could be asked whether this is indeed an acceptable strategy in terms of social welfare maximisation and long-term sustainability considerations.

Development Path B poses an alternative to A, and implements "expensive" bulk-water supply options at an earlier stage. This development path challenges current decision-making and cost-estimation methodologies by questioning the relative cost of "expensive" options compared to alternatives if all costs could be quantified and included in the equation. 


\subsection{Spatial expansion}

Although not the only water resource management authority in the BWMA, the City of Cape Town (CCT) is by far the biggest in terms of volume of use and number of users. More than $90 \%$ of the City's water supplies originate from outside the municipal boundaries of the CCT, which makes the CCT dependent on the surrounding rural areas for its water supply. Such a situation has the potential for the development of conflicting interests between different user groups. The spatial dimensions were therefore expanded via an expansion of the physical boundary of the decision-making context to include all rural areas sharing water resources with the CCT.

With such an expansion the dynamics of long-term water management, including resource scarcity, demand elasticities, substitutability, time, representation, emotion, and politics, all came into play, staging a complex management challenge and thereby significantly adding to the information load of the decision-making process. The spatial expansion was accommodated via a public survey, an expert panel survey and increased representation of key decision-makers.

\section{Expert and public surveys}

Two separate surveys were undertaken. The first focused on identifying public preferences with regard to long-term water management, and this fed into the second (expert panel survey), focussing on a weighted score for the development paths.

Political transparency played an important role in the development of both surveys because ignorance of political impacts in the survey development process had the potential to harm the legitimacy of the results. The study therefore incorporated the political process running parallel with the study from the beginning. This did slow the study somewhat to allow for the democratic process, but it strengthened the expectation that the research findings would be politically acceptable.

\subsection{Public survey}

Public enquiry was undertaken by means of a survey in the expanded area, focussing on the determination of public preference regarding the two development paths as mentioned in Table 1. A conjoint-analysis-based approach was followed. The method collects and analyses individual preferences for goods and services (in this case it was a public good - bulk-water supply) and assumes that each scheme may be described in terms of its characteristics or attributes to society and the natural environment. This study settled for a onepage full-profile presentation to keep the response rate as high as possible and the presented information focussed only on the indication of differences between the two development paths.

A budget limitation allowed a sample of approximately 7000 questionnaires, representing a $2.55 \%$ stratified sample of a population of 275012 data entries. 
Samples equal to the representative size of suburbs/regions were drawn. The public was confronted with key expected impacts/outcomes of the two developments paths and were asked to indicate their relative preference for each development path via a scoring system.

\subsection{Expert panel survey}

Fifty potential expert respondents were invited to participate in the expert panel survey. Participation entailed an electronic survey via e-mail and a personal interview for discussion and verification. This was followed by a final followup. Each expert was asked to score the two development paths in terms of five main criteria groups. A criteria weight allocation exercise was also included, and each expert was also asked to estimate the outcome of the public survey.

The selection of criteria was crucial for obtaining a legitimate answer. An extensive list of criteria could be used to describe the two development paths; however, not all were relevant to the decision-making process. It was decided that only differentiating criteria would be used to distinguish between the two development paths. Five main criteria groups were identified and included in the study:

- Water balance, with two sub-criteria: confidence in the yield and timing of yield.

- Finances, with three sub-criteria: unit reference value (URV); confidence in the accuracy of cost estimations and changes in tariffs necessary to maintain service.

- Socio-economics included six sub-criteria: dependency on natural rainfall; volume of water allocated from rural to urban areas; impacts on agricultural production and employment; multipliers; urbanisation and recreation and tourism.

- $\quad$ The Environment criteria group proved to be a controversial topic. Five sub-criteria were included: in-stream flow requirements; waste disposal and the dilution effect of rivers; groundwater recharge and discharge tempos; flood and erosion control and impacts on biodiversity.

- $\quad$ Public acceptance was accommodated as a separate criteria group, via the public survey.

Care was taken to ensure correct interpretation of questions. All expert comments were noted and compiled into a single questionnaire that was used in the follow-up session, when the expert panel was given the opportunity to respond to one another's comments. All comments were kept anonymous and were used to guide the statistical analysis and inference.

\section{Results}

\subsection{Public survey}

The two developments paths were compared only in terms of the five main criteria groups to allow for simplicity and the length of the questionnaire. 
Respondents were asked to indicate their preference for A and B in the form of a total score out of 100 (higher score indicates higher preference).

Table 2: $\quad$ Descriptive statistics for the public and expert panel surveys.

\begin{tabular}{|l|r|r|r|r|}
\cline { 2 - 5 } \multicolumn{1}{c|}{} & \multicolumn{2}{c|}{ Public survey } & \multicolumn{1}{c|}{ Expert estimations } \\
\hline \multicolumn{1}{c|}{ Descriptive statistics } & DP A & DP B & \multicolumn{1}{c|}{ DP A } & \multicolumn{1}{c|}{ DP B } \\
\hline Mean & 38.563 & 61.438 & 44.118 & 55.882 \\
\hline Standard Error & 0.772 & 0.772 & 4.314 & 4.314 \\
\hline Median & 35 & 65 & 40 & 60 \\
\hline Mode & 40 & 60 & 60 & 40 \\
\hline Standard Deviation & 25.473 & 25.473 & 17.787 & 17.787 \\
\hline Sample Variance & 648.853 & 648.853 & 316.360 & 316.360 \\
\hline Kurtosis & -0.363 & -0.363 & -0.923 & -0.923 \\
\hline Skewness & 0.475 & -0.475 & -0.431 & 0.431 \\
\hline Range & 100 & 100 & 60 & 60 \\
\hline Minimum & 0 & 0 & 10 & 30 \\
\hline Maximum & 100 & 100 & 70 & 90 \\
\hline Sum & 41956 & 66844 & 750 & 950 \\
\hline Count & 1088 & 1088 & 17 & 17 \\
\hline
\end{tabular}

Table 2 presents some descriptive statistics from the public survey as well as comparative expert estimations. The outcome of the public survey yields a preference to Development Path B (and therefore a "greener" water allocation strategy) in the proportional size of $60: 40$ by all three indicators of relative location. It was decided that the mean score of 38.56 for Development Path A (and 61.44 for B) would be used in the aggregation process, followed afterwards in the expert panel survey (see Table 3). Mean and median expert panel estimations approximate the outcome of the public survey while the mode was the exact opposite, indicating outliers (or possible disagreement) in expert opinion.

It must be noted that no generalisation could be made whatsoever with regard to the comparison of the obtained public preference and expert panel estimations since the comparative outcome will always be a function of the issue at handalthough possible, no statistical analysis with regard to the comparison of the public preferences and expert panel estimations of such preferences was made. The important point is that public preferences were consulted and not assumed.

\subsection{Expert panel survey}

Normal probability plots (not shown) indicated that a significant number of criteria were non-normally distributed. A significant variation regarding the score and weight structures were evident among the experts. This implies a relatively low level of consensus among the experts regarding the level of importance of the different criteria. This difference was, however, expected since the panel was composed of experts in different fields of interest.

The relative location of the different distributions was of lesser importance than the weighted scores of the two development paths. A single parameter representing each criteria group distribution was needed thereby forcing normality on the distributions. Overall scores of the two development paths were determined by aggregating the weighted scores obtained from the 
individual criteria after the individual expert scores for each criteria were multiplied with the relative importance (weight of the particular criteria among all experts) of that criteria (see Table 3). The mean, mode and median were used for comparative calculations. Answers of the same magnitude were obtained, with the mean presenting the most balanced view of the criteria for displaying purposes.

Table 3: $\quad$ Aggregated score for Development Paths A and B (mean).

\begin{tabular}{|c|c|c|c|c|c|c|c|}
\hline \multirow{2}{*}{ Main criteria } & \multirow[b]{2}{*}{ Sub criteria: } & \multirow[b]{2}{*}{ weight } & \multirow[b]{2}{*}{ cumulative weight } & \multicolumn{2}{|c|}{ score (unweighted) } & \multicolumn{2}{|c|}{ score (weighted) } \\
\hline & & & & $\mathrm{A}$ & $\mathrm{B}$ & $A$ & $\mathrm{~B}$ \\
\hline & & $100.00 \%$ & $22.06 \%$ & & & & \\
\hline & Confidence in yield & $52.94 \%$ & $11.91 \%$ & $38.74 \%$ & $61.26 \%$ & $4.61 \%$ & $7.30 \%$ \\
\hline & Timing (ability to supply the demand) & $47.06 \%$ & $10.15 \%$ & $36.98 \%$ & $63.02 \%$ & $3.75 \%$ & $6.39 \%$ \\
\hline \multirow[t]{4}{*}{ Financial aspects } & & $100.00 \%$ & $24.24 \%$ & & & & \\
\hline & URV & $38.94 \%$ & $9.08 \%$ & $68.16 \%$ & $31.84 \%$ & $6.19 \%$ & $2.89 \%$ \\
\hline & Confidence in total cost estimates & $30.35 \%$ & $7.46 \%$ & $46.57 \%$ & $53.43 \%$ & $3.47 \%$ & $3.99 \%$ \\
\hline & Tariff changes necessary to maintain & $30.71 \%$ & $7.70 \%$ & $63.14 \%$ & $36.86 \%$ & $4.86 \%$ & $2.84 \%$ \\
\hline \multirow[t]{7}{*}{ Socio-economic aspects } & & $100.00 \%$ & $17.82 \%$ & & & & \\
\hline & Dependency on natural rainfall & $22.13 \%$ & $3.93 \%$ & $15.28 \%$ & $84.72 \%$ & $0.60 \%$ & $3.33 \%$ \\
\hline & Volume of water allocated from rural to & $13.02 \%$ & $2.33 \%$ & $26.70 \%$ & $73.30 \%$ & $0.62 \%$ & $1.70 \%$ \\
\hline & Impacts on agricultural production and & $29.56 \%$ & $5.27 \%$ & $38.20 \%$ & $61.80 \%$ & $2.01 \%$ & $3.26 \%$ \\
\hline & Multipliers & $12.55 \%$ & $2.53 \%$ & $40.62 \%$ & $59.38 \%$ & $1.03 \%$ & $1.50 \%$ \\
\hline & Urbanisation & $11.55 \%$ & $1.70 \%$ & $41.35 \%$ & $58.65 \%$ & $0.70 \%$ & $0.99 \%$ \\
\hline & Recreation and tourism & $11.19 \%$ & $2.07 \%$ & $44.48 \%$ & $55.52 \%$ & $0.92 \%$ & $1.15 \%$ \\
\hline \multirow[t]{6}{*}{ Environmental aspects } & & $100.00 \%$ & $26.47 \%$ & & & & \\
\hline & Expected impacts on IFR & $31.06 \%$ & $8.57 \%$ & $27.04 \%$ & $72.96 \%$ & $2.32 \%$ & $6.25 \%$ \\
\hline & Waste disposal and dilution effect & $17.35 \%$ & $4.46 \%$ & $34.23 \%$ & $65.77 \%$ & $1.53 \%$ & $2.93 \%$ \\
\hline & Ground water recharge. & $17.53 \%$ & $4.35 \%$ & $40.87 \%$ & $59.13 \%$ & $1.78 \%$ & $2.57 \%$ \\
\hline & Flood and erosion control & $10.00 \%$ & $2.74 \%$ & $54.40 \%$ & $45.60 \%$ & $1.49 \%$ & $1.25 \%$ \\
\hline & Loss of Biodiversity & $24.06 \%$ & $6.36 \%$ & $35.91 \%$ & $64.09 \%$ & $2.28 \%$ & $4.08 \%$ \\
\hline \multirow[t]{2}{*}{ Public acceptance } & & $100.00 \%$ & $9.41 \%$ & $38.56 \%$ & $61.44 \%$ & $3.63 \%$ & $5.78 \%$ \\
\hline & & & $100.00 \%$ & & & $41.80 \%$ & $58.20 \%$ \\
\hline
\end{tabular}

The outcome of the public survey was used as an unweighted score in calculating the public acceptance score in Table 3 - it is therefore assumed that the expert estimation differed significantly from the obtained preference of the public survey. This point is debatable, though. However, all three indicators (mean, mode and median) presented a majority for Development Path B. The outcome of the two surveys therefore suggests that Development Path B was the preferred option, suggesting a legitimate willingness to pay for "greener" water and public acceptance for increased water tariffs to accommodate the implementation of such strategies. Care must, however, be taken to use the outcome of this study as a "sweeping-statement" to promote the desalination of seawater or recycling to potable standard as an alternative water supply option for the CCT.

\section{Conclusions}

The outcome of the two surveys differed from previous MCDM runs that yielded preferences for "conventional" bulk supply schemes. After expanding the decision-making context a higher willingness to pay for "greener" allocations was noted, suggesting that an expansion of decision-making contexts along with decision-support will promote social welfare even if not all costs and benefits could be quantified. Legitimate presentation of total costs through the promotion of political transparency safeguarded against bias with regard to representation of the impacts of different allocations. The importance of decision-makers not 
focussing exclusively on direct costs was shown, as this could lead to bias and unsustainable resource allocation decision-making.

A measurement problem with potentially serious consequences in terms of sustainable resource utilisation is evident in the management of public goods such as bulk-water supply infrastructure. Such a measurement problem hinders the consideration of the true costs and benefits of different long-term management options and strategies implying decision-making with incomplete information. Special reference was made to the issue of public participation as a source of the incomplete information that characterises the management of bulkwater supply infrastructures as a public good.

The decision-making context was expanded to promote the quality of decision-making information. Spatial and temporal expansions were presented, and the importance of consulting the public regarding their preferences in allocation decisions (as opposed to assuming what their preferences are) was highlighted.

Theory suggests a principal-agent relationship between public and water managers, but in this case, a reversed principal-agent relationship with a parted principal for the same agent was encountered. Agents certainly need to accommodate the public in the decision-making process without verifying the long-term planning ability of the principal. This could be done by confronting the public with a prospective but legitimate and objective management option and then consult their preferences. The relative success of presenting a legitimate option depend on the ability of the agent to make future trade-offs with the information available to him and to communicate a complex management problem in a simple, objective and understandable way in order to obtain a meaningful answer from the public.

An acceptance of water tariff increases and therefore a willingness to pay for "greener" water was displayed. However, a narrow tariff resource base to absorb tariff increases could lead to an increase in the current non-payment problem. The increase in water tariffs for "greener" water is a typical example of a comparison of a direct cost against an indirect benefit. The outcome is therefore an educational problem, where user education should explain that by sacrificing now, great benefits (in the forms of future cost savings or future benefits) might be realised in future.

The study confirmed a principal-agent relationship in resource allocation management but also a reversed form of this relationship in long-term water resource allocation decision-making. Agents should involve the public in longterm water management decision-making. The challenge is to develop communication strategies that are consistent over time and space and communicate clearly and effectively. Education plays an important role in the public's ability to absorb information and present legitimate preference orderings. An educational process to promote insight into the measurement problem is therefore justified - such an education process will also positively affect the non-payment problem and the promotion of environmental education to foster insight into the measurement problem could be justified. It would also positively affect the non-payment problem. 


\section{References}

[1] Arriaza M, Gomez-Limon JA \& Upton M (2002). Local water markets for irrigation in southern Spain: A multi-criteria approach. Australian Journal of Agricultural and Resource Economics 46(1):21-43.

[2] Arrow K (1984). Formal theories of social welfare. Collected papers of Kenneth Arrow: Social choice and justice, Oxford, UK.

[3] Bateman IA, Lovett AA \& Brainard JS (2003). Applied environmental economics. Cambridge University Press, UK.

[4] Bergson A (1954). On the Concept of Social Welfare. Quarterly Journal of Economics.

[5] Bush DB, Martin WE \& Brown TC (1987). Do water market prices appropriately measure water values? Natural Resource Journal 27(3):617651.

[6] Carmichael SS, Forsyth D \& Hughes DA (2001). Decision support system for the development of rural water supply schemes. Water Research Commission, Report No: 837/1/01, Pretoria.

[7] Colby BG, Crandall K \& Bush DB (1993). Water right transactions: Market values and price dispersion. Water Resource Research 29(6):1565-1572.

[8] Dudley NJ (1992). Water allocation by markets, Common property and capacity-sharing: Companions or Competitors? Natural Resources Journal 32(4):757-778.

[9] Easter KW, Dinar A \& Rosegrant M (1998). Markets for water: Potential and performance. Kluwer Academic Press, Massachusetts.

[10] Fishelson G (1994). The water market in Israel: An example for increasing the supply. Resource and Energy Economics 16(4):321-334.

[11] Fisher FM, Arlosoroff S, Eckstein Z, Haddadin M, Hamati SG, Huber-Lee A \& Jarrar A (2002). Optimal water management and conflict resolution: The middle east water project. Water Resources Research 38(1):1-16.

[12] Goodstein ES (1999). Economics and the environment. Prentice Hall Publishers, New Jersey.

[13] Keenan SP, Krannich RS \& Walker MS (1999). Public perceptions of water transfers and markets: Describing differences in water use communities. Society and Natural Resources 12:279-292.

[14] Kloezen W (1998). Water markets between Mexican water user associations. Water Policy 1:437-455.

[15] Kumar M \& Singh O (2001). Market instruments for demand management in the face of scarcity and overuse of water in Gujarat, Western India. Water Policy 3:387-403.

[16] Livingston ML (1995). Designing water institutions: Market failures and institutional response. Water Resources Management 9(203-220).

[17] Louw DB (2002). The development of a methodology to determine the true value of water and the impact of a potential water market on the efficient utilisation of water in the Berg River basin. Water Research Commission, Report No: 943/1/02, Pretoria. 
[18] Mander M, Cox D, Turpie J \& Breen C (2002). Incorporating economic considerations into quantification, allocation and management of the environmental water reserve. Water Research Commission, Report No: 978/1/02, Pretoria.

[19] Nieuwoudt WL (2000). Water market institutions: Lessons from Colorado. Agrekon 39(1):58-67.

[20] Pearce DW (1993). Economic values and the environment. The MIT Press, UK.

[21] Randall A (1983). The problem of market failure. Natural Resource Journal 23:131-148. 